\title{
Exercise promotes satellite cell contribution to myofibers in a load-dependent manner
}

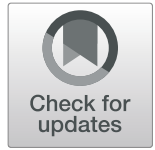

\author{
Evi Masschelein ${ }^{1 \dagger}$, Gommaar D’Hulst ${ }^{1 \dagger} \mathbb{D}^{\mathbb{D}}$, Joel Zvick${ }^{2}$, Laura Hinte ${ }^{3}$, Inés Soro-Arnaiz ${ }^{1}$, Tatiane Gorski ${ }^{1}$, \\ Ferdinand von Meyenn ${ }^{3}$, Ori Bar-Nur ${ }^{2}$ and Katrien De Bock ${ }^{1^{*}}$
}

\begin{abstract}
Background: Satellite cells (SCs) are required for muscle repair following injury and are involved in muscle remodeling upon muscular contractions. Exercise stimulates SC accumulation and myonuclear accretion. To what extent exercise training at different mechanical loads drive SC contribution to myonuclei however is unknown.

Results: By performing SC fate tracing experiments, we show that 8 weeks of voluntary wheel running increased SC contribution to myofibers in mouse plantar flexor muscles in a load-dependent, but fiber type-independent manner. Increased SC fusion however was not exclusively linked to muscle hypertrophy as wheel running without external load substantially increased SC fusion in the absence of fiber hypertrophy. Due to nuclear propagation, nuclear fluorescent fate tracing mouse models were inadequate to quantify SC contribution to myonuclei. Ultimately, by performing fate tracing at the DNA level, we show that SC contribution mirrors myonuclear accretion during exercise.

Conclusions: Collectively, mechanical load during exercise independently promotes SC contribution to existing myofibers. Also, due to propagation of nuclear fluorescent reporter proteins, our data warrant caution for the use of existing reporter mouse models for the quantitative evaluation of satellite cell contribution to myonuclei.
\end{abstract}

Keywords: Satellite cell, Fusion, Exercise, Load, Running, Fate tracing, Myonuclei

\section{Background}

Muscle tissue has a remarkable ability to adapt its structure and microenvironment in response to diverse conditions such as injury, contractile activity, mechanical overload, and nutrients [1-3]. Satellite cells (SCs) are a unique population of stem cells that remain quiescent for the majority of time but upon activation can proliferate asymmetrically and fuse with myofibers [4]. It has been hypothesized that SCs play a supportive role in muscular remodeling by exercise, because SC accumulation as well as myonuclear accretion have been observed

\footnotetext{
* Correspondence: katrien-debock@ethz.ch

'Evi Masschelein and Gommaar D'Hulst contributed equally to this work. 'Department Health Sciences and Technology, Laboratory of Exercise and Health, Swiss Federal Institute of Technology (ETH) Zurich, Zurich, Switzerland

Full list of author information is available at the end of the article
}

during episodes of hypertrophy [5-8]. Yet, the quantitative extent of SC contribution to myonuclei was not demonstrated by these studies. Genetic lineage experiments, in which Pax $7^{+}$cells and their derived fibers are fluorescently labeled, have recently shown that there is a considerable (up to 30\%) contribution of SCs to uninjured adult mouse skeletal muscle fibers $[9,10]$. To what extent SCs fuse with existing myofibers during exercise and whether SC fusion mirrors myonuclear accretion under different exercise intensities (with different load) remains to be elucidated.

While there is accumulating data showing SC are required for muscle hypertrophy $[6,8]$ the functional role of SCs in muscle endurance adaptations is much less understood [11]. Running exercise increases the number of myofibers containing an elevated number of SCs [12, 13], and SC number is directly proportional to running

\section{BMC}

(c) The Author(s). 2020 Open Access This article is licensed under a Creative Commons Attribution 4.0 International License, which permits use, sharing, adaptation, distribution and reproduction in any medium or format, as long as you give appropriate credit to the original author(s) and the source, provide a link to the Creative Commons licence, and indicate if changes were made. The images or other third party material in this article are included in the article's Creative Commons licence, unless indicated otherwise in a credit line to the material. If material is not included in the article's Creative Commons licence and your intended use is not permitted by statutory regulation or exceeds the permitted use, you will need to obtain permission directly from the copyright holder. To view a copy of this licence, visit http://creativecommons.org/licenses/by/4.0/ The Creative Commons Public Domain Dedication waiver (http://creativecommons.org/publicdomain/zero/1.0/) applies to the data made available in this article, unless otherwise stated in a credit line to the data. 
performance [14]. Nevertheless, SC number but not myonuclear number increased in several rat hind limb muscles after a period of free wheel running [15]. Moreover, no defects in intrinsic adaptations to endurance exercise (e.g., muscle vascularization, fiber type shift, or succinate dehydrogenase activity) were reported when SCs were ablated using the Pax CreERT2-DTA model or Xray irridation, arguing against the necessity of SCs for adaptations to endurance exercise [16, 17]. Consequently, it is currently unknown whether exercise training aimed to evoke endurance adaptions, but not muscle hypertrophy, stimulates $\mathrm{SC}$ contribution to myonuclei.

An excellent model to study the involvement of SCs in muscle adaptations to exercise is voluntary wheel running. Mice have a strong intrinsic drive to run large distances in their active phase [18], which keeps stress and mouse handling at a minimum. Furthermore, by applying resistance to the running wheel, muscle hypertrophy can be induced [19-25], and reducing wheel resistance (free running) leads to favorable endurance adaptations without pronounced effects on muscle hypertrophy [16, 26]. Thus, using this exercise model in combination with genetic lineage tracing experiments of SCs, we aimed to evaluate whether SC contribution to myonuclei is mediated by increasing load during exercise training and whether this manifests in SC-mediated myonuclear accretion.

\section{Methods}

\section{Animals}

All mice were housed in individually ventilated cages (3-4 littermates per cage) at standard housing conditions $\left(22{ }^{\circ} \mathrm{C}, 12 \mathrm{~h}\right.$ light/dark cycle), with ad libitum access to chow (KlibaNafag, diet \#3436 and diet \#3437) and water. Health status of all mouse lines was regularly monitored according to FELASA guidelines. All mouse lines were maintained on a C57BL/6J background: Pax7CreERT2 (Jackson labs stock no. 017763), Rosa ${ }^{m T m G}$ (Jackson labs stock no. 007576), and Rosa CAG-LSL-ntdTomato (Ai75D, Jackson labs stock no. 025106). Rosa ${ }^{m T m G}$ and

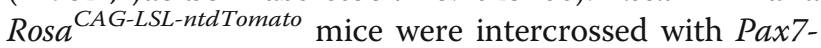
CreERT2 mice to generate Pax $7^{\mathrm{CreERT2/+}}$, Rosa $a^{\text {mTmG/+ }}$ $\left(\operatorname{Pax} 7^{m T m G /+}\right)$ and Pax $7^{\text {CreERT2/+ }}$, and Rosa ${ }^{\text {CAG-LSL-ntdTo- }}$ mato/+ $\left(\right.$ Pax $\left.7^{n T o m /+}\right)$. All mice used in this study were female. At the age of 15 weeks, mice received tamoxifen via intraperitoneal injection at a dose of $1.0 \mathrm{mg} /$ day for 5 days to induce Cre-mediated recombination, and a washout period of 7 days was allowed before experiments were initiated.

\section{Experimental procedures}

All animal procedures were approved by the veterinary office of the Canton of Zürich (license nr. ZH254-16). Mice were individually housed in open cages equipped with a running wheel device (TSE Systems, Bad Homburg vor der Höhe, Germany) for the duration of the intervention. Non-running control mice were also singly housed in cages of equal dimensions but without running wheels. The running wheel device continuously records wheel movements out of which total distance $(\mathrm{km})$, speed $\left(\mathrm{m} . \mathrm{s}^{-1}\right)$, number of running bouts, and resistance on the wheel $(N)$ were extracted. Additionally, to increase the force needed to rotate the wheel, resistance $(0-100 \%)$ can be added. To calculate total external work, we used the equation $W=P t$ where $W$ is work, $P$ is power, and $t$ is time. To calculate the power of the wheel at each braking resistance, we used the equation $P=$ $2 \pi \times f \times M$ where $f$ is the angular frequency of the wheel, and $M$ is the torque at a given braking resistance. TSE Systems provided a torque braking resistance curve. Mice were randomized in three groups: sedentary controls (no running), voluntary low load endurance wheel running where there is no extra resistance on the wheel (VRun), and voluntary high load resistance wheel running where extra resistance is placed on the wheel (VResRun). A representation of the study design is shown in Fig. 1a. Prior to the 8 weeks of voluntary wheel running, both groups VRun and VResRun were familiarized for 5 days to the running wheel without extra resistance. After familiarization, the VResRun group was subjected to a progressive weekly increase in resistance on the wheel: The load on the wheel was $50 \%$ in week 1 , $60 \%$ in week $2,70 \%$ in week $3,72 \%$ in week 4 , and $74 \%$ from weeks 5 to 8 . The minimal distance which mice needed to run was set at $2 \mathrm{~km}$ per night. In case a mouse did not reach $2 \mathrm{~km}$ for 2 consecutive nights, resistance was slightly reduced for 3 nights after which it was raised again. All mice ran at $74 \%$ resistance during the last 2 weeks.

\section{Sample collection}

Tissue collection was performed $24 \mathrm{~h}$ after the last exercise session after a 4-h fast. Mice were anaesthetized using Ketamine $(80-100 \mathrm{mg} / \mathrm{kg})$, Xylazine $(10-15 \mathrm{mg} /$ $\mathrm{kg}$ ), and Acepromazine $(2-5 \mathrm{mg} / \mathrm{kg})$ via intraperitoneal injection $5 \mathrm{~min}$ before sacrifice. The depth of anesthesia was confirmed by testing pedal withdrawal reflex. Subsequently, the $\mathrm{m}$. soleus (SOL), m. plantaris (PLT), $\mathrm{m}$. gastrocnemius (GAS), $\mathrm{m}$. tibialis anterior (TA), and $\mathrm{m}$. extensor digitorum longus (EDL) were harvested, weighed, and frozen in OCT embedding matrix (CellPath) in liquid nitrogen-cooled isopentane for histochemical analysis or fixed in 4\% PFA for single myofiber isolation. Tibia length was assessed by a digital caliper. After sample collection, animals were euthanized, and major bleeding was induced to confirm death. 


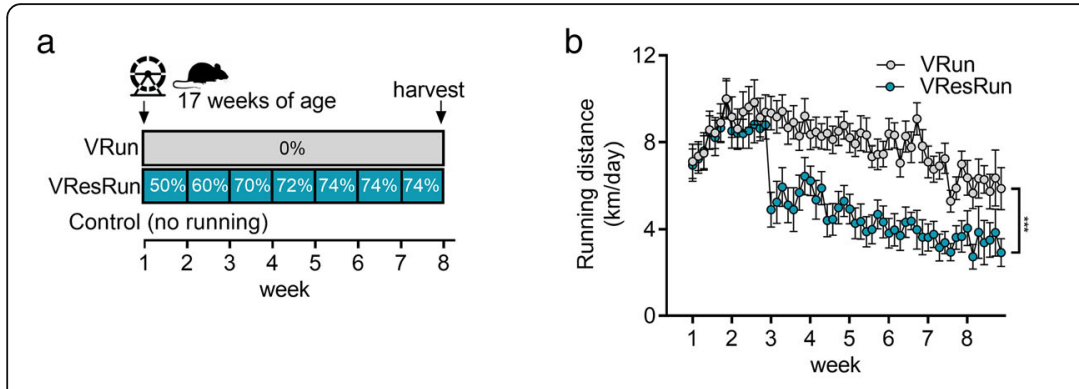

d

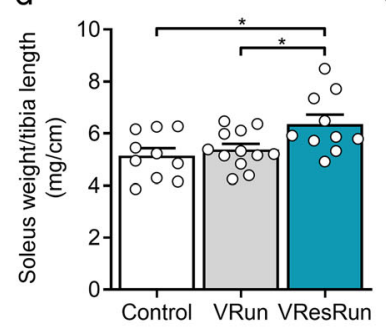

e
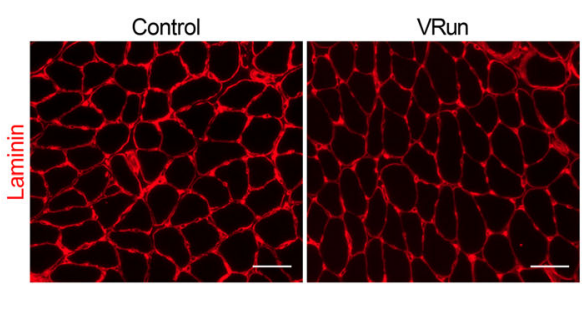

$\mathrm{h}$

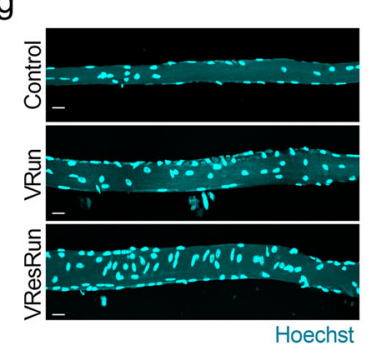

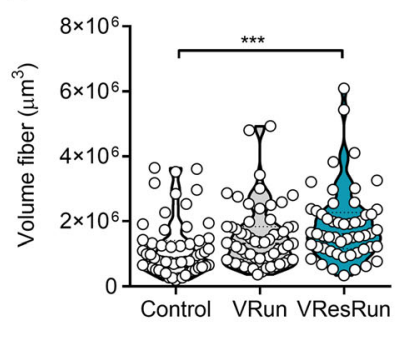

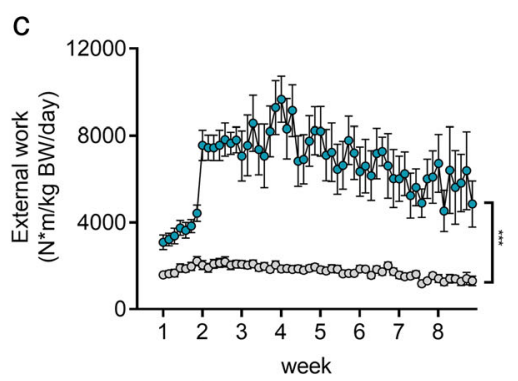

f
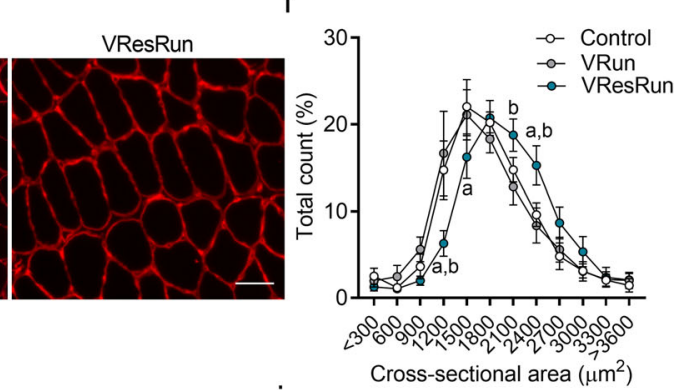

i

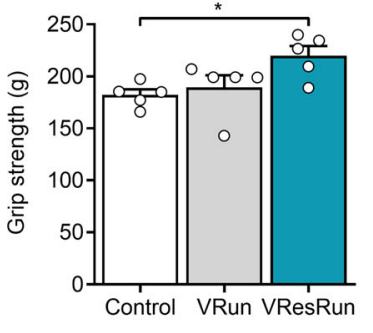

j

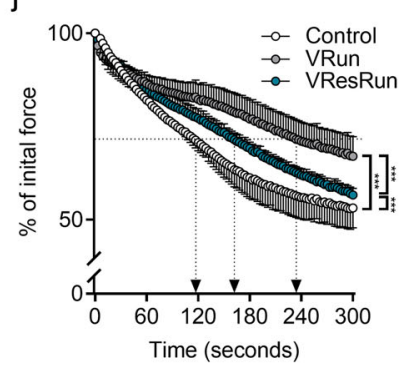

Fig. 1 Running pattern and muscle hypertrophy are load-dependent. a Experimental set-up. b Average running distances and c average external work per night throughout the exercise protocol ( $n=16$ mice per group). $\mathbf{d}$ Soleus weight normalized to tibia length. e Representative cross-sections stained for laminin (red) and $\mathbf{f}$ quantification ( $n=7-8$ mice per group) of fiber cross-sectional area distribution in soleus muscle. $\mathbf{g}$ Representative pictures of single myofibers isolated from soleus and (h quantification of fiber volume of 11-16 single myofibers per mouse ( $n=4$ mice per group). $\mathbf{i}$ Muscle force production by grip strength and $\mathbf{j}$ time-to-fatigue in ex vivo stimulated muscle. Statistics, one-way ANOVA test with Tukey correction for multiple comparisons $(\mathbf{d}, \mathbf{h}, \mathbf{i}, \mathbf{j})$ or two-way ANOVA test with a Bonferroni post hoc test $(\mathbf{b}, \mathbf{c}, \mathbf{f}, \mathbf{k}) .\left({ }^{*} p<0.05 ;{ }^{* *} p<0.01 ;{ }^{* * *} p<0.001\right)$. Each dot represents a single mouse $(\mathbf{d}, \mathbf{i}, \mathbf{j})$ or muscle fiber $(\mathbf{h})$. Bar graphs $(\mathbf{d}, \mathbf{i}, \mathbf{j})$ and line graphs $(\mathbf{b}, \mathbf{c}, \mathbf{f}, \mathbf{k})$ represent mean \pm SEM (error bars). Violin plot (h). Scale bars, $50 \mu \mathrm{m}(\mathbf{e})$ and $25 \mu \mathrm{m}(\mathbf{g})$. Pax $7^{\mathrm{mTmG/+}}$ female mice on a C57BL/6J background were used for all analyses

\section{Immunofluorescence}

Frozen sections $(10 \mu \mathrm{m})$ of muscle embedded in OCT of mid-belly level were made using a cryostat (Leica CM 1950) and collected on Superfrost Ultra Plus slides (Thermo Scientific, Zug, Switzerland). The following antibodies were used: anti-MyHC-I (1:50 dilution, BA-F8 from hybridoma, Iowa City, IA, USA), anti-MyHC-IIa (1:200 dilution, SC-71 from hybridoma), anti-MyHC-IIb (1:100 dilution, BF-F3 from hybridoma), anti-laminin (1:200 dilution, PA1-16730, ThermoFisher), anti-PCM1 (1:1000 dilution, HPA023370, Sigma, Buchs, Switzerland), eMHC (1:20 dilution, F1.652 from hybridoma), Alexa Fluor 488 goat anti-mouse IgG2B (1:250 dilution, ThermoFisher), Alexa Fluor 350 goat anti-mouse IgG1 (1:250 dilution, A21120, ThermoFisher), Alexa Fluor 568 goat anti-mouse IgM (1:250 dilution, A-21043, ThermoFisher), Alexa Fluor 647 goat anti-rabbit IgG (1:250 dilution, A-21244,
ThermoFisher), Alexa Fluor 568 goat anti-mouse IgG1 (1: 400 dilution, A-21124, ThermoFisher), and Alexa Fluor 647 conjugated wheat germ agglutinin (WGA, 1:50 dilution, W32466, ThermoFisher).

Immunohistochemical muscle fiber staining was conducted as previously described [27]. In short, sections were dried and washed for $5 \mathrm{~min}$ in PBS supplemented with $0.05 \%$ Triton-X-100 (PBST) and subsequently blocked for $60 \mathrm{~min}$ in PBST $+10 \%$ goat serum (16210064, ThermoFisher). Afterwards a primary antibody cocktail diluted in PBST $+10 \%$ goat serum was applied for $120 \mathrm{~min}$ against MyHC-I, MyHC-IIa, MyHCIIb, and laminin. After washing 3 times for $5 \mathrm{~min}$, a secondary antibody cocktail, diluted in PBST $+10 \%$ goat serum, was applied for $60 \mathrm{~min}$. Slides were mounted after a $3 \times 5$ min wash and sealed with glass cover slips. A similar protocol was used for eMHC. Sections were 
dried and washed for 5 min in PBST and subsequently blocked for $60 \mathrm{~min}$ in PBST $+10 \%$ goat serum (16210064, ThermoFisher). Sections were stained overnight at $4{ }^{\circ} \mathrm{C}$ with eMHC (F1.652) and laminin diluted in PBST $+10 \%$ goat serum. Next day after washing 3 times for $5 \mathrm{~min}$, anti-mouse and anti-rabbit secondary antibodies were diluted in PBST $+10 \%$ goat serum for $1 \mathrm{~h}$. Slides were mounted. For myonuclear staining, samples were stained with anti-PCM1 as previously described [28]. Slides were pre-incubated in 2\% BSA in PBS. Sections were stained with a rabbit polyclonal antibody against PCM1 in staining solution (5\% BSA in PBS, $0.2 \%$ Triton-X-100) overnight at $4{ }^{\circ} \mathrm{C}$. The next day, the sections were washed three times for $5 \mathrm{~min}$ in PBS and stained with an anti-rabbit secondary antibody in $2 \%$ BSA in PBS for $1 \mathrm{~h}$. Sections were washed three times for 10 min with PBS. For detection of the fiber boundaries, the sections were stained with WGA in PBS for 30 min. Nuclei were co-stained using Hoechst dye 33342 (dilution 1:5000, H3570, ThermoFisher).

Images from sections were captured at $\times 10$ using an epifluorescent microscope (Zeiss Axio observer Z.1, Zeiss, Oberkochen, Germany). Composite images were stitched together using the tiles module in the ZEN 2011 imaging software (Zeiss). All images were captured at the same exposure time. Approximately 100 (SOL, PLT) and 200 (GAS) muscle fibers, divided in different regions over the whole muscle section, were analyzed for $\mathrm{PCM}^{+} /$Hoechst $^{+}$nuclei with the Zen software (ZEN 2011 imaging software, Zeiss).

Satellite cell contribution to myofibers in $\operatorname{Pax} 7^{m T m G /+}$ mice was quantified based on a previously described method of myofiber masking [29]. Tilescan images were processed using an Image-J plug-in to define myofiber cross-sectional area (CSA) [30], followed by a manual refinement of the CSA outlines. An overlay of those outlines on the corresponding mGFP image was performed, after which the data was compiled in Excel, and a threshold was set for the mean gray value of mGFP. A frozen section isolated from a vehicle-treated mouse (negative control sample) was used to determine the threshold and to ensure the elimination of autofluorescence. mGFP images were overlaid with the muscle fiber type staining to identify $\mathrm{mGFP}^{+}$oxidative $(\mathrm{MyHCI})$ and glycolytic (MyHCIIa, MyHCIIb, and MyHCIIx) fibers.

\section{Single myofiber isolation}

For single myofiber analysis, the SOL from the $\operatorname{Pax} 7^{n-}$ $\mathrm{Tom} /+$ mice was harvested, fixed in $4 \%$ paraformaldehyde/PBS for $1 \mathrm{~h}$ at $4{ }^{\circ} \mathrm{C}$ and transferred to PBS containing $2 \%$ horse serum. To release individual myofibers, single fibers were mechanically teased apart, strained, and washed with PBS. Isolated single myofibers were stained with Hoechst for nuclear visualization and gently mounted on a glass coverslip. Images were captured at $\times 10$ using a confocal microscope (Olympus olympus fluoview FV 3000, Olympus, Hamburg, Germany). Eleven to sixteen fibers per mouse from random areas from the muscle were analyzed. Total number of nTom ${ }^{+}$nuclei and Hoechst ${ }^{+}$nuclei along $500 \mu \mathrm{m}$ fiber length were quantified using a spot detection algorithm developed in Imaris (Bitplane). Myofiber volume was approximated as the volume of a cylinder using the average radius measured along the fiber length in Imaris. Fibers isolated from vehicle-treated mice were used to set a threshold to ensure the elimination of autofluorescence.

\section{Cell culture}

\section{Reagents}

Freshly isolated primary myoblasts were cultured in growth medium, which contained a 1:1 ratio DMEM (ThermoFisher Scientific, 12320032) and Ham's F-10 nutrient mix (ThermoFisher Scientific, 22390058) supplemented 20\% FBS (Thermo Scientific, 10270106) and 10 ng/ml basic-FGF (ThermoFisher Scientific, PHG0266). Cells were differentiated in low-serum differentiation medium (Thermo Scientific, 41965039), supplemented with 2\% horse serum (Thermo Scientific, 16050-122). Cells were routinely cultured in $21 \% \mathrm{O}_{2}$ and $5 \% \mathrm{CO}_{2}$. Every other day, differentiation medium was changed until myotubes reached full differentiation. All media were supplemented with 100 units $/ \mathrm{ml}$ penicillin and $100 \mu \mathrm{g} / \mathrm{ml}$ streptomycin.

\section{Isolation of SCs/myoblasts}

Isolation of SCs/myoblasts was done as previously described [31]. Briefly, muscle tissue was digested in Hank's Balanced Salt Solution (HBSS, Thermo Fisher, 24020117) supplemented with $1.5 \%$ bovine serum albumin (BSA) and $2 \mathrm{mg} / \mathrm{ml}$ collagenase type II (ThermoFisher Scientific, 17101015) for $1 \mathrm{~h}$ at $37{ }^{\circ} \mathrm{C}$. After centrifugation, the cell pellet was then filtered using $100-$ and $40-\mu \mathrm{m}$ cell strainers, and a heterogeneous cell population was purified by FACS sorting or by serial preplating. For FACS, SCs were sorted based on positive alpha 7-integrin (1:100, R\&D Systems FAB3518P) and absence of Sca1 (1:1000, Bio-Legend 122511), CD31 (1: 1000, Bio-Legend, 102413), and CD45 (1:1000, BioLegend 103121).

\section{Generation of nuclear H2B-GFP (H2B-nGFP) myoblasts}

Lentivirus was generated with PEG-it Virus Precipitation Solution (System Biosciences, Palo Alto, CA, USA no LV810A-1) using a LV H2B-GFP plasmid (Addgene no 25999) in HEK 293 cells. Myoblasts were transfected with $20 \mu \mathrm{l}$ of concentrated lentivirus for $24 \mathrm{~h}$ using growth medium supplemented with $4 \mu \mathrm{g} / \mathrm{ml}$ polybrene transfection reagent (TR1003-G, Sigma-Aldrich). 


\section{Co-culturing experiments}

$\mathrm{nTom}^{+}$myoblasts, together with committed WT myoblasts, were co-cultured at 1:4 ratio $\left(\mathrm{nTom}^{+} / \mathrm{WT}\right) . \mathrm{nTom}^{+}$ myoblasts were co-cultured with myoblasts stably expressing $\mathrm{H} 2 \mathrm{~B}-\mathrm{nGFP}$ at a ratio of $1: 1$ ratio $\left(\mathrm{nTom}^{+} / \mathrm{H} 2 \mathrm{~B}-\right.$ nGFP $^{+}$). Two hours after seeding, growth medium was changed to differentiation medium. Every other day, differentiation medium was changed until myotubes reached full differentiation, and immunofluorescent images were taken every $24 \mathrm{~h}$ via an epifluorescent microscope, equipped with a cell incubator (Nikon eclipse Ti2, Nikon, Amstelveel, Netherlands). Fluorescent pictures were captured every $15 \mathrm{~min}$ to generate a time-lapse video (Windows movie maker, Windows, Redmond, WA, US).

\section{SC fate tracing at the DNA level using RT-PCR for Cre- mediated recombination in bulk muscle and sorted myonuclei}

To perform SC fate tracing at the DNA level, genomic DNA was isolated from muscle or myonuclei using QIAamp DNA Micro and Mini Kit (Qiagen, Hilden, Germany). Myonuclei were isolated as previously described [32]. Nuclei were isolated with EZ PREP buffer (Sigma, NUC-101). Frozen soleus muscles $(10 \mathrm{mg})$ were homogenized using a glass dounce tissue grinder in $2 \mathrm{ml}$ of ice-cold EZ PREP and incubated on ice for $5 \mathrm{~min}$, with an additional $2 \mathrm{ml}$ of ice-cold EZ PREP and filtered through a $100-\mu \mathrm{m}$ cell strainer. Nuclei were centrifuged at $500 \times g$ for $5 \mathrm{~min}$ at $4{ }^{\circ} \mathrm{C}$, washed with $4 \mathrm{ml}$ ice-cold EZ PREP, and incubated on ice for $5 \mathrm{~min}$. After centrifugation, the nuclei were stained for $45 \mathrm{~min}$ with an antibody against PCM-1 (1:1500, HPA023370, Sigma), followed by an Alexa647-anti-rabbit secondary antibody for $30 \mathrm{~min}$ (1:1500) and Hoechst 33342 (1:5000), and filtered through a $35-\mu \mathrm{m}$ cell strainer. Hoechst ${ }^{+}$and Alexa647 ${ }^{+}$ myonuclei were directly sorted into RLTplus buffer (Qiagen). A final amount of 10,000-20,000 nuclei was used for genomic DNA isolation. A SYBR Green-based master mix (ThermoFisher Scientific, A25778) was applied for RT-PCR analysis. Recombination rates were calculated from the relative expression of recombined levels normalized to an internal control. The delta-delta CT method was used to normalize the data. The percentage recombination was calculated relative to positive controls. To generate a positive control, we crossed $H S A^{\text {CreERT2 }}$ mice [33] with $\operatorname{Rosa}^{m T m G}$ mice to generate $H S A^{\text {CreERT2/+}}$; Rosa ${ }^{m T m G /+}$ mice. In these mice, tamoxifen injection leads to the excision of mTomato from the DNA in myonuclei and the subsequent expression of $m$ GFP. Additionally, we sorted SCs from $\operatorname{Pax} 7^{n T o m} /+$ mice. The following primers were used to detect recombination (see also Fig. 5a, b): $\operatorname{Ros}^{m T m G}$, recombined amplicon: Fw5'- GGGCTCGACACTAGTGAACC-3' Rv 5'-GGTGATGATCCGGAACCCTT-3', Internal control:
Fw 5'-AGCGAACGGACAGGAGAATG-3', Rv 5'ACTTGTGGCCGTTTACGTCG-3', $\quad$ Rosa CAG-LSL-ntdTomato, recombined amplicon: $\mathrm{Fw}$ 5'-TTATTGTGCT GTCTCATCATTTTGG-3' Rv 5'-CTTCGCGAGA CCGGTAATCT-3', Internal control: Fw5'- CTGTTC CTGTACGGCATGG-3' Rv 5'-GGCATTAAAGCAGC GTATCC-3'.

\section{Grip strength}

Grip strength of the limbs was measured using a force tension apparatus (grip strength meter, Bioseb, Vitrolles, France) after 8 weeks of voluntary wheel running or no running. Mice were lifted by the tail and were made to hold a metal grid with all limbs. Total limb maximal grip strength was registered in gram during three consecutive attempts, and the result was set as the average of the attempts.

\section{Ex vivo muscle force assay}

The SOL was carefully dissected and placed in KrebsHenseleit buffer $(120 \mathrm{mM} \mathrm{NaCl}, 4.8 \mathrm{mM} \mathrm{KCl}, 25 \mathrm{mM}$ $\mathrm{NaHCO} 3, \quad 2.5 \mathrm{mM} \quad \mathrm{CaCl} 2, \quad 1.2 \mathrm{mM}$ KH2PO4, $2 \mathrm{mM}$ $\mathrm{MgSO} 4$ ) supplemented with $25 \mathrm{mM}$ glucose at $37{ }^{\circ} \mathrm{C}$ and bubbled with $95 \% \mathrm{O}_{2}-5 \% \mathrm{CO}_{2}$ to stabilize the $\mathrm{pH}$ at 7.4. The distal tendon was securely connected to a fixed bottom plate and the proximal tendon to the arm of a servomotor (800A in vitro muscle apparatus, Aurora Scientific). Muscle length was adjusted until a single stimulus pulse elicited maximum force during a twitch (optimal length, Lo) under isometric conditions. After $15 \mathrm{~min}$ of equilibration, a fatigue protocol was started. To fatigue the muscle, tetanic contractions of $60 \mathrm{~Hz}$ were produced, once every $2 \mathrm{~s}$, for a total of $300 \mathrm{~s}$. Timeto-fatigue at $75 \%$, an assessment for the time it takes for a muscle to fall to $75 \%$ of its initial force, was calculated for every mouse.

\section{Statistical analysis}

Statistical significance was determined by a one-way ANOVA with Tukey correction for multiple comparisons or two-way ANOVA with Bonferroni correction with Graphpad Prism 8.2. Data are presented as means \pm SEM, and values of $p<0.05$ were considered statistically significant. The degree of significance is depicted as follows: ${ }^{*} p<0.05,{ }^{* * *} p<0.01$, and ${ }^{* * * *} p<0.001$.

\section{Results}

Running pattern, hypertrophy, and muscle performance in VRun vs. VResRun

To study how increased load during exercise affects contribution of SCs to myofibers, we used 8 weeks of voluntary low load-endurance type-running (VRun) and voluntary high load-resistance type-running (VResRun) as exercise models (Fig. 1a). A progressive increase in 
load reduced running distance (Fig. 1b), running speed, and total daily running time without affecting the number of running bouts from week 3 onwards (Figure S1AC). In contrast, external work was higher over the 8week time period (Fig. 1c). In agreement with previous observations [23, 24, 34], extra resistance on the wheel caused an increase in the weight of $\mathrm{m}$. soleus (SOL), while unloaded running did not change SOL weight (Fig. 1d). Body weight, lean mass, and fat mass were not affected by exercise (Table S1). Further analysis on cross-sectional area (CSA) confirmed that VResRun, but not VRun, induced fiber hypertrophy in SOL (Fig. 1e, f). This was exclusively caused by an increase in the CSA of MyHCIIa muscle fibers, while MyHCI fiber CSA remained unaffected (Figure S2A-E). Finally, in accordance with the data on whole muscle, VResRun increased the volume of isolated single myofibers from SOL, while VRun did not affect myofiber volume (Fig. 1g, h).

Despite unchanged muscle weight in PLT (Table S1), we measured increased fiber CSA in PLT upon VResRun as well as VRun. CSA of MyHCIIa fibers increased both after VRun and VResRun compared to control, whereas MyHCIIb-IIx fiber CSA only increased after VResRun (Figure S2F-J). The discrepancy between muscle mass and CSA in the PLT could be due to difficulties in anatomically dissecting the muscle [35]. Muscle mass of $\mathrm{m}$. gastrocnemius (GAS), $\mathrm{m}$. tibialis anterior (TA), and $\mathrm{m}$. extensor digitorum longus (EDL) remained unaffected by VRun and VResRun (Table S1). In addition, no change in fiber CSA was found for GAS, TA, and EDL (Figure S2K,L,M). We also performed immunofluorescent stainings for embryonic myosin heavy chain (eMHC) on VRun and VResRun SOL muscle samples, using glycerol injected muscle as a positive control. We however could not detect $\mathrm{eMHC}^{+}$fibers in VRun nor VResRun whereas extensive $\mathrm{eMHC}^{+}$fibers were detected in glycerol damaged muscle (Figure S3A). This shows that at the time of muscle sampling ( 8 weeks of running), no active regeneration was ongoing. Subsequently, we also evaluated the number of centrally nucleated fibers. We observed similar fractions of nucleated fibers in both VRun as well as VResRun, whereas negligible centrally nucleated fibers were observed under control conditions (Figure S3B). A discrepancy between eMHC and centrally nucleated fibers has been observed before upon synergist ablation and tenotomy [36]. Potentially, this can be the sign of ongoing fiber splitting or other myofiber remodeling processes which do not necessarily requires satellite cells [36].

Finally, to analyze whether VResRun resulted in different functional adaptations when compared to VRun, we tested functional strength (grip strength) as well as muscle endurance capacity. After 8 weeks, grip strength was increased in VResRun (Fig. 1i), showing that
VResRun increased functional strength. In addition, time-to-fatigue at $75 \%$, an assessment for the time it takes for an ex vivo stimulated muscle to fall to $75 \%$ of its initial force, was higher after VRun and VResRun compared to control (Fig. 1j), indicating that free running improved intrinsic muscle endurance capacity. Collectively, these data confirm that VResRun, but not VRun, induces an increase in muscle mass in both SOL and PLT, which was induced by hypertrophy of the glycolytic muscle fibers. On the other hand, VRun leads to more pronounced endurance adaptations.

\section{Exercise promotes SC contribution to myofibers in a load- dependent manner}

To investigate whether voluntary wheel running affects $\mathrm{SC}$ contribution to various hind limb muscles, and whether this is load-dependent, we genetically labeled SCs and performed fate-tracing experiments into myonuclei. To do so, we used a mouse model which was previously used to study SC involvement in muscle regeneration [37] and muscle homeostasis [9]. Briefly, we intercrossed $\operatorname{Pax} 7^{\text {CreERT2/CreERT2 }}$ mice, which efficiently induces recombination in SCs, with mice carrying a Rosa $a^{m T m G / m T m G}$ reporter [38]. The resulting Pax7$\mathrm{CreERT2/+}^{2}$; Rosa ${ }^{m T m G /+}$ mice $\left(\operatorname{Pax} 7^{m T m G /+}\right)$ ubiquitously express membrane-bound Tomato (mTomato), but following tamoxifen injection, Cre-mediated recombination results in the excision of mTomato and expression of membrane-bound GFP ( $m G F P)$ in SCs. In these mice, the presence of $\mathrm{GFP}^{+}$myofibers indicates that at least one $\mathrm{SC}$ fused with those myofibers. In our experiments, we labeled SCs by 5 consecutive daily IP tamoxifen injections and initiated the exercise protocol 1 week later. Subsequently, hind limb muscles were harvested after 8 weeks of VRun or VResRun or no running (control) (Fig. 2a), and the contribution of SCs to myofibers was evaluated. Importantly, we opted to use 15 weeks old mice for all our experiments since this is an age where postnatal muscle growth has ceased and SC contribution to myofibers is restricted to maintenance of muscle homeostasis [10, 36, $39-41]$. Indeed, in agreement with previous work $[9,10]$, we found that in the non-exercising control mice, 5-20\% of all myofibers were $\mathrm{GFP}^{+}$, with the highest contribution of SCs in the SOL, confirming that SC fusion occurs in hind limb muscles of sedentary mice (Fig. 2b-d). Interestingly, running increased the SC contribution to SOL, PLT, and GAS, whereas we did not observe a clear increase in SC contribution to fibers upon exercise in TA, nor EDL (Fig. 2b-d), confirming previous observations from our group that wheel running specifically recruits the hind limb plantar flexors [42]. Moreover, SC contribution to the SOL was load-dependent, as VResRun further increased the number of $\mathrm{GFP}^{+}$myofibers compared to VRun alone, resulting in $80 \% \mathrm{GFP}^{+}$myofibers vs. $60 \%$ 


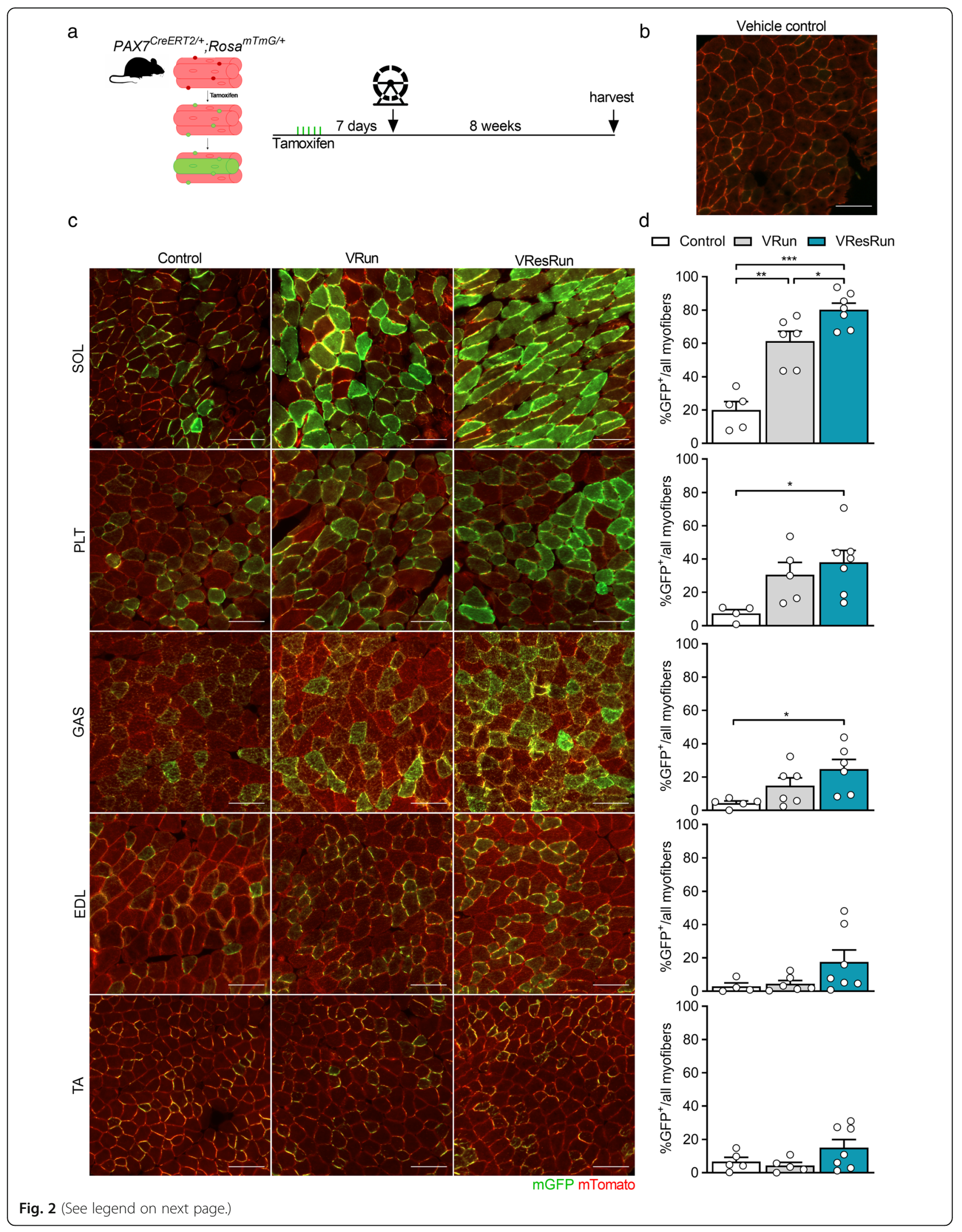


(See figure on previous page.)

Fig. 2 Exercise promotes SC contribution to myofibers in a load-dependent manner. a Pax XreERT2 mice were crossed with Rosa ${ }^{m T m G}$ mice to genetically trace SC fusion to myofibers. Upon tamoxifen treatment SCs will express mGFP. mGFP ${ }^{+}$myofibers indicate fusion of SCs. $\mathbf{b}$ A cryosection from a vehicle-treated mouse (negative control sample) was used to determine the threshold and to ensure the elimination of autofluorescence. $\mathbf{c}$ Representative cross-sections of soleus (SOL), plantaris (PLT), gastrocnemius (GAS), tibialis anterior (TA), and extensor digitorum longus (EDL) muscle showing GFP ${ }^{+}$myofibers to which SCS contributed. d Quantification of GFP+ myofibers. Statistics, one-way ANOVA test with Tukey correction for multiple comparisons $\left({ }^{*} p<0.05 ;{ }^{* *} p<0.01 ;{ }^{* * *} p<\right.$ 0.001). Each dot represents a single mouse. Bar graphs represent mean \pm SEM (error bars). Scale bar, $100 \mu \mathrm{m}$

in VRun condition. In PLT and GAS, we also observed a $38 \%$ increase in $\mathrm{GFP}^{+}$myofibers upon VResRun, while the increase by VRun did not reach statistical significance (Fig. 2b-d).

To investigate whether the increase in SC contribution to myofibers by exercise was different between fiber types, we made sequential cryosections of SOL, overlaid the GFP signal with fiber type immunostainings, and assessed the relative amount of $\mathrm{GFP}^{+}$fibers to MyHC type (Figure S4A). VResRun induced the largest increase in $\mathrm{GFP}^{+}$fibers resulting in $~ 80 \%$ of all MyHCI and MyHCIIa fibers becoming GFP positive, while this was only 60\% in VRun, indicating that 8 weeks of increased load promoted SC contribution to myofibers but that there was no fiber type preference (Figure $\mathrm{S} 4 \mathrm{~B}, \mathrm{C})$. Moreover, in agreement with previous data [43], both running modalities led to a shift towards a more oxidative fiber type $(\mathrm{MyHCI})$ with the largest shift in the VRun group (Figure S4D). Thus, because we observed similar contribution of SCs to MyHCI versus MyHCIIa, relative GFP contribution after exercise mirrored the shift in fiber type (Figure S4E). Altogether, we show that exercise drives $\mathrm{SC}$ contribution to muscle fibers in a load-dependent manner but independent of muscle fiber type.

\section{Nuclear propagation renders nuclear reporter mice inadequate to assess SC contribution to myonuclei} Our data from the $\operatorname{Pax} 7^{m T m G /+}$ mice indicated that exercise strongly increases SC contribution to myofibers. Nevertheless, this model does not allow us to assess the exact number of SCs that fuse with the myofiber since the GFP signal diffuses throughout the sarcolemma, nor does it provide information on myonuclear accretion upon exercise training. Therefore, we generated a nuclear reporter mouse by crossing the aforementioned $\operatorname{Pax} 7^{C r E E R T 2}$ with a Rosa ${ }^{C A G-L S L-n t d T o m a t o}$ mouse. The Rosa CAG-LSL-ntdTomato mouse expresses a loxP-flanked stop codon before the nuclear tdTomato fluorescent red (nTom) reporter. Upon tamoxifen injection, the nuclear stop codon is excised to indelibly label $\operatorname{Pax} 7^{+} \mathrm{SCs}$ and their derivative nuclei with nTom (Fig. 3a). We used the Pax $7^{C r E E R T 2 /+}$; RosaCAG-LSL-ntdTomato/+ $\left(\right.$ Pax $\left.^{n \text { Tom } /+}\right)$ mice to assess myonuclear accretion and SC contribution to myonuclei.

First, by isolating single muscle fibers from SOL (Fig. 3a) after 8 weeks of exercise training, we found that VResRun, and to a lesser extent VRun, increased the number of Hoechst ${ }^{+}$nuclei on single fibers compared to control by respectively 16 and $14 \%(p<0.05$ and $p=$ 0.05 , Fig. 3b). Subsequently, we also analyzed myonuclear content on cryosections using a myonuclear-specific PCM1 staining. Stainings on SOL sections corroborated these findings (Figure S5A-B). Additionally, we also found a load-dependent increase in myonuclear content in PLT and GAS (Figure S5A-B). Intriguingly, compared to myonuclear $\left(\right.$ Hoechst $^{+}$) accretion, we observed a much larger increase in $\mathrm{nTom}^{+}$nuclei after both VRun $\left(+1.8\right.$ Hoechst $^{+}$ nuclei vs. $+7.0 \mathrm{nTom}^{+}$nuclei per $100 \mu \mathrm{m}$ fiber length) and VResRun $\left(+2.0\right.$ Hoechst $^{+}$nuclei vs. +8.3 nTom $^{+}$nuclei per $100 \mu \mathrm{m}$ fiber length) on single fibers (Fig. 3b-d), suggesting (1) high turnover of myonuclei during exercise or (2) nuclear reporter mice are inadequate to measure SC fusion in myocytes due to nuclear travelling of nTom, a process recently termed "propagation" by Taylor-Weiner et al. [44]. To investigate the latter hypothesis, we performed a series of in vitro co-culturing experiments. In a first experiment, we cultured $\mathrm{nTom}^{+}$myoblasts together with myoblasts which stably expressed GFP in the nucleus (H2B-nGFP) at a 1:1 ratio and differentiated them to myotubes for $144 \mathrm{~h}$ (Fig. 4a). In this experiment, protein propagation between nuclei in multinucleated myotubes would lead to nTom $+/ \mathrm{H} 2 \mathrm{~B}-\mathrm{nGFP}^{+}$myonuclei. Timecourse imaging revealed that once $\mathrm{H} 2 \mathrm{~B}-\mathrm{nGFP}^{+}$and $\mathrm{nTom}^{+}$myoblast started to fuse, double positive nuclei (yellow) became apparent, resulting in $45 \%$ of all nuclei that turned double positive for H2B-nGFP and nTom at full differentiation (Fig. 4b, c), showing that there is reporter protein propagation. Since only limited number of SCs contribute to myonuclei in myofibers in vivo, we performed a second experiment, where we cultured nTom ${ }^{+}$ myoblasts together with committed myocytes which do not express a reporter protein (WT) at a ratio of 1:4 $\left(\mathrm{nTom}^{+} / \mathrm{WT}\right)$ and further differentiated them to myotubes for $144 \mathrm{~h}$ (Fig. 4d). Even though myoblasts completely stop proliferating $48 \mathrm{~h}$ after initiation of differentiation (data not shown), sequential imaging showed that an increasing fraction of nuclei became positive for nTom over the 144$\mathrm{h}$ follow-up period (Fig. $4 \mathrm{e}-\mathrm{g}$ ). In fact, while less than $30 \%$ of nuclei were $n$ Tom $^{+} 48 \mathrm{~h}$ after the start of the experiment, almost $60 \%$ of all nuclei were $\mathrm{nTom}^{+}$at $144 \mathrm{~h}$ (Fig. 4e). Altogether, this data shows that as soon as SC fuse to existing fibers and contribute to the myonuclear pool, during in vitro differentiation or in vivo following exercise, proteins from the newly acquired myonuclei propagate to 


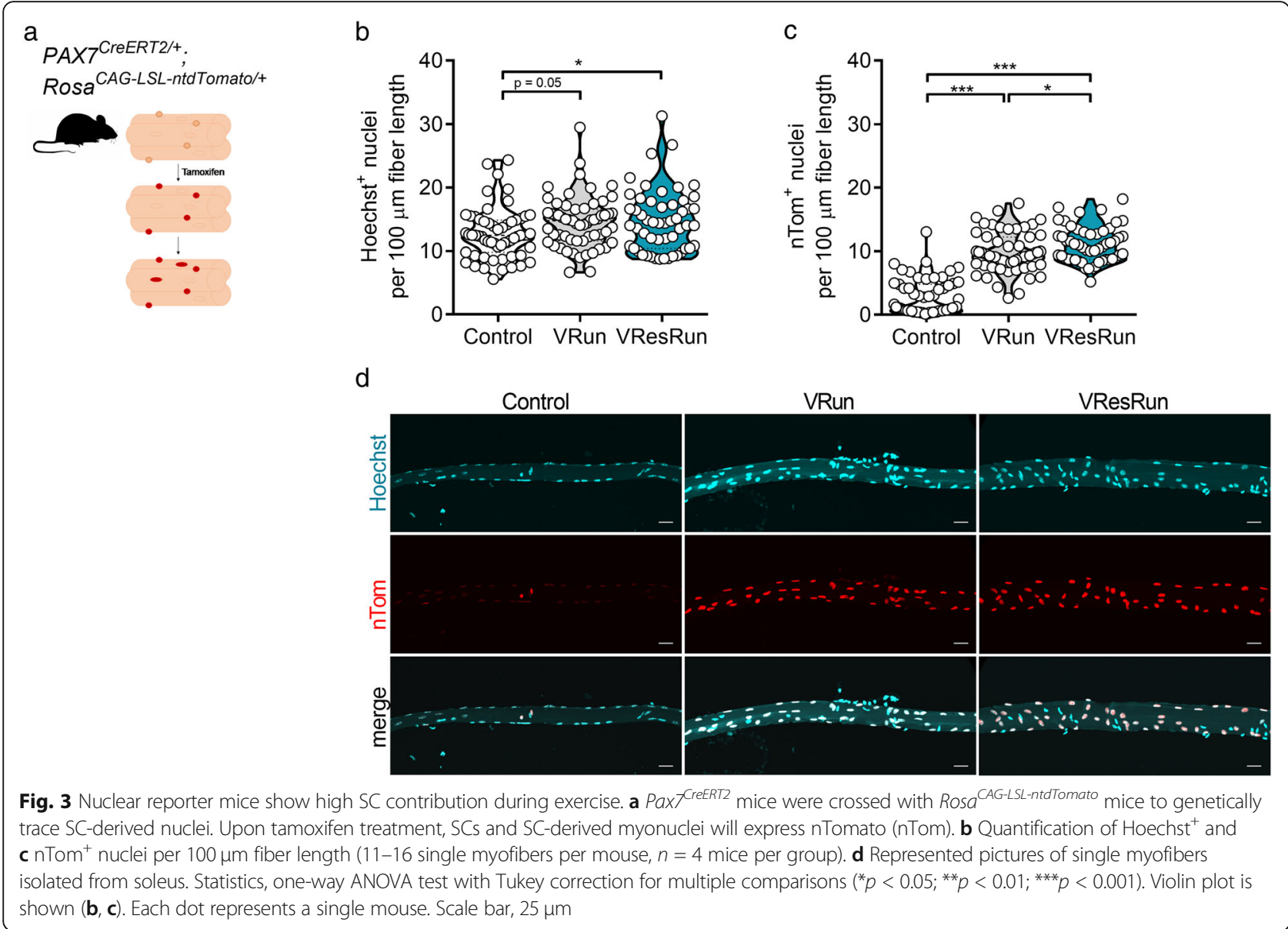

old residing myonuclei within the same myofiber. In addition, we also observed that the original $\mathrm{nTom}^{+}$myoblasts expressed higher levels of nTom when compared to the nTom levels in the differentiated cells, suggesting that nTom protein was diluted between nuclei (Fig. 4f). Finally, time-lapse microscopy imaging showed that propagation occurs at very fast rates, as nTom was transported towards neighboring $\mathrm{nTom}^{-}$myonuclei within $15 \mathrm{~min}$ of myoblast fusion (Video S1). In conclusion, it is not possible to determine the exact number of SCs that contribute to myonuclei using common lineage tracing reporter models.

\section{SC fate tracing at the DNA level confirms load-dependent $\mathrm{SC}$ fusion during exercise}

Since our data shows that counting the number of $\mathrm{nTom}^{+}$nuclei in $\mathrm{Pax}^{\text {nTom/t }}$ mice does not allow to evaluate the exact contribution of SCs to myonuclei during exercise, we used a RT-PCR on genomic DNA to measure Cre-mediated recombination. This allows to trace the fate of SC at the DNA level. To this end, we sorted Hoechst ${ }^{+} / \mathrm{PCM1}^{+}$myonuclei from $\mathrm{Pax} 7^{n \mathrm{Tom} /+}$ control, VRun, and VResRun mice (SOL muscle) (Fig. $5 \mathrm{~b}$ ) and isolated DNA from these myonuclei. We designed primers specific for the recombined sequence and an internal control (housekeeping gene) (Fig. 5a). We found almost 20\% recombination after 8 weeks of VResRun, indicating that $20 \%$ of all myonuclei were recombined, while only $12 \%$ and $4 \%$ recombination was observed in VRun and control respectively (Fig. 5c). To further substantiate these data, we extracted genomic DNA from bulk muscle (SOL) from control, VRun, and VResRun $\operatorname{Pax}^{m T m G /+}$ mice and observed a similar loaddependent increase in SC contribution to nuclei upon exercise (Fig. 5d, e). Collectively, these observations show that mechanical load during exercise independently promotes SC contribution to existing myofibers which manifests in myonuclear accretion.

\section{Discussion}

Satellite cells are required for muscle regeneration and in addition contribute to muscle homeostasis under sedentary conditions $[9,10]$, but how they contribute to training adaptations is still poorly understood. Using two $\mathrm{SC}$ fate tracing mouse models, we show that exercise promotes the contribution of SCs to myofibers in a load-dependant manner. Moreover, we found that SC 


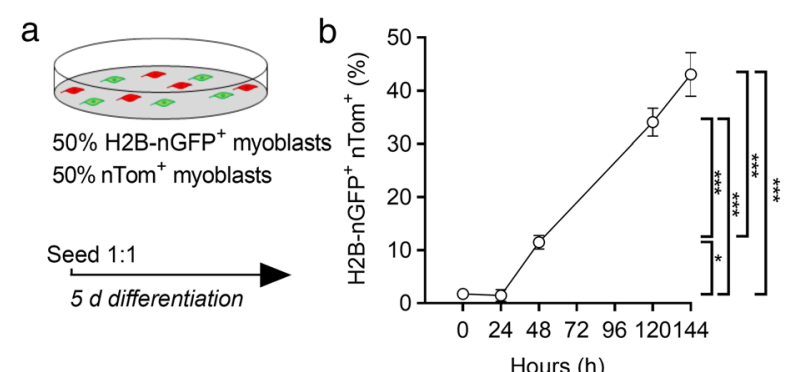

C

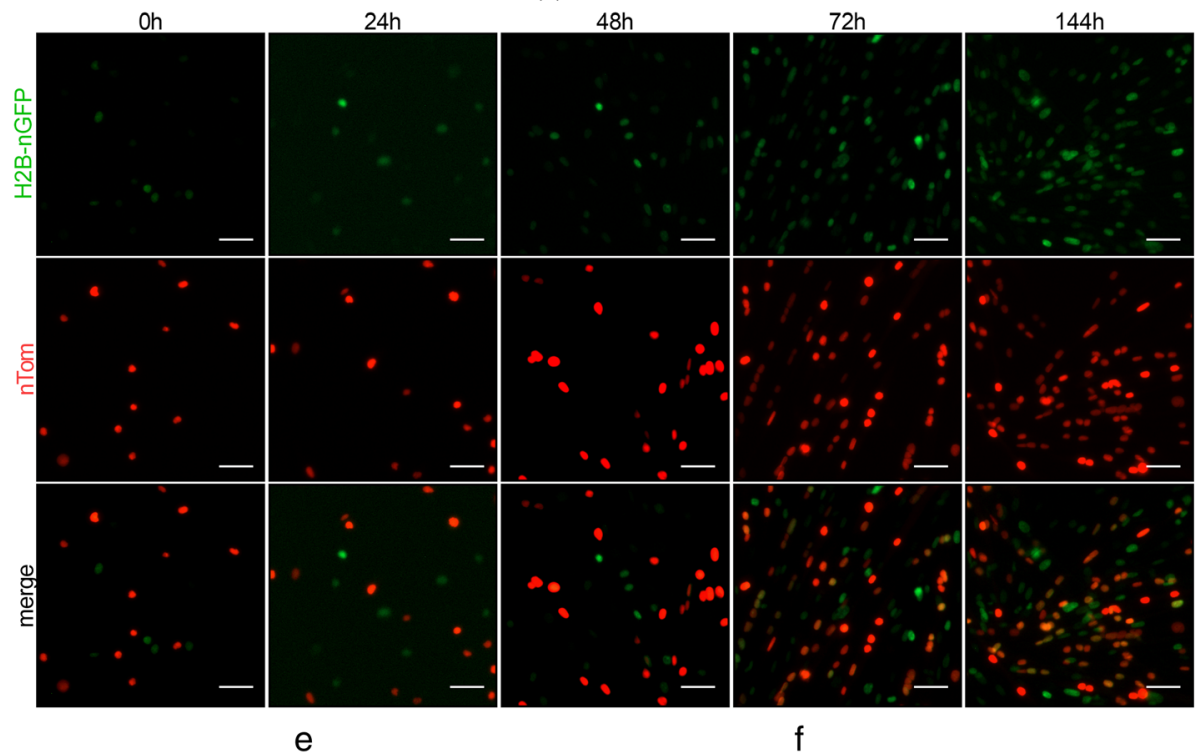

d

e

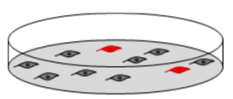

$80 \%$ WT myoblasts $20 \%$ nTom $^{+}$myoblasts

Seed Seed

WT nTom $^{+}$
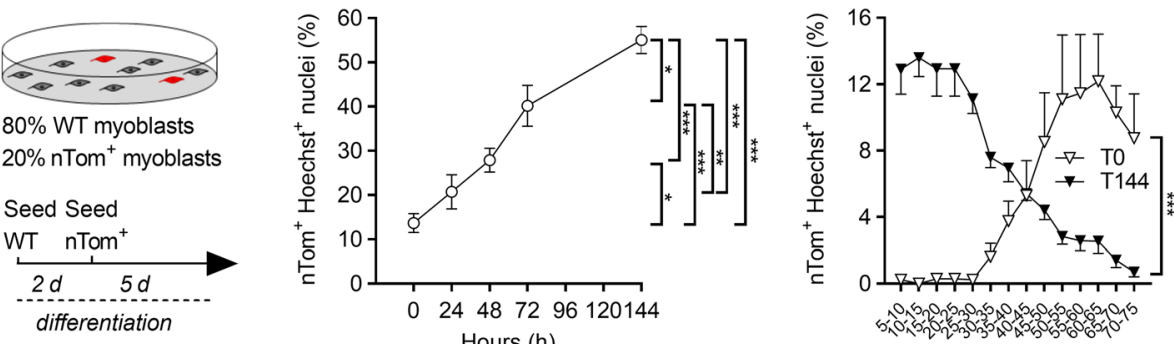

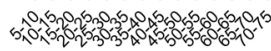

Intensity (AU)

g

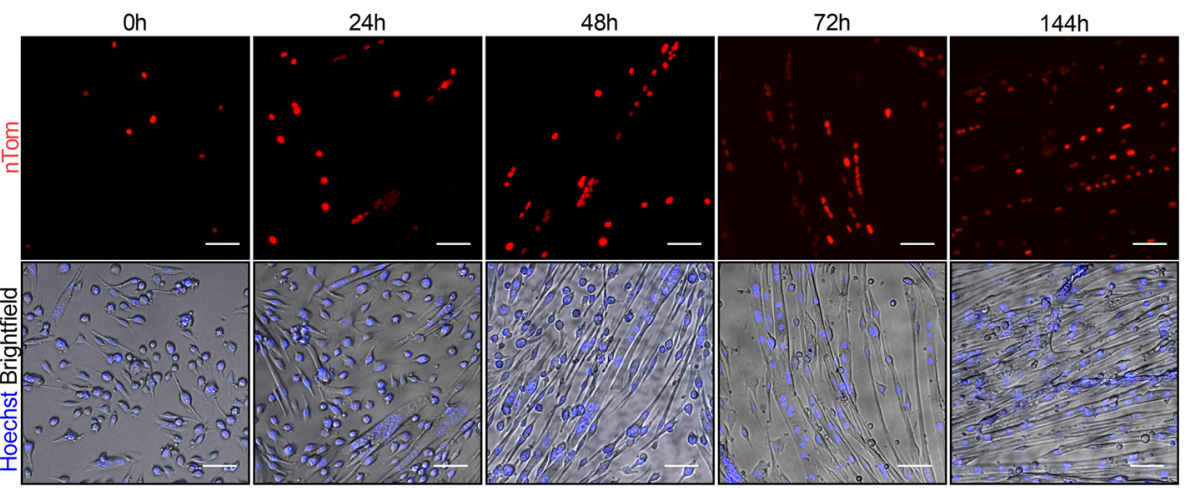

Fig. 4 (See legend on next page.) 
(See figure on previous page.)

Fig. 4 Fluorescent nuclear protein propagation renders reporter mice inadequate to assess SC fusion in myofibers. a Nuclear H2B-nGFP expressing and $\mathrm{nTom}^{+}$myoblast were seeded at 1:1 ratio and differentiated for $144 \mathrm{~h}$. b Double positive nuclei for $\mathrm{H}_{2} \mathrm{~B}-\mathrm{nGFP}^{+}$and $\mathrm{nTom}^{+}$ (marked in yellow) were assessed over time in relation to total nuclei (Hoechst ${ }^{+}$). $\mathbf{c}$ Representative pictures of H2B-nGFP ${ }^{+}$and nTom ${ }^{+}$myoblast co-cultures over time. $\mathbf{d} \mathrm{nTom}^{+}$and committed WT myoblast were seeded at a 1:4 ratio and differentiated for $144 \mathrm{~h}$. e Double positive nuclei for $\mathrm{nTom}^{+}$and Hoechst ${ }^{+}$were assessed over time in relation to total nuclei $\left(\mathrm{Hoechst}^{+}\right)$. $\mathbf{f} \mathrm{nTom}$ intensity was measured $1 \mathrm{~h}$ after seeding (T0) and upon full differentiation (T144). Data is represented as percentage of $\mathrm{nTom}^{+}$nuclei per intensity range in relation to the total nTom ${ }^{+}$nuclei. $\mathbf{g}$ Representative pictures of WT and nTom ${ }^{+}$myoblast co-cultures over time. Statistics, one-way ANOVA test with Tukey correction for multiple comparisons $\left({ }^{*} p<0.05 ;{ }^{* *} p<0.01 ;{ }^{* *} p<0.001\right)$. Bar graphs represent mean \pm SEM (error bars). Scale bar, $50 \mu m$

contribution to myofibers is present to a similar extent in oxidative and glycolytic muscle fibers.

Mice which ran against an external load (VResRun) showed higher SC contribution when compared to free runners (VRun). Notwithstanding, VRun extensively increased SC fusion without stimulating fiber hypertrophy.
In agreement with other studies [34], we found clear hypertrophy after resistance running but no consistent increases in fiber size/volume after voluntary running: SOL wet weight did not increase, fiber cross sectional area was not changed, and we also did not observe an increase in SOL single fiber volume after VRun. Some

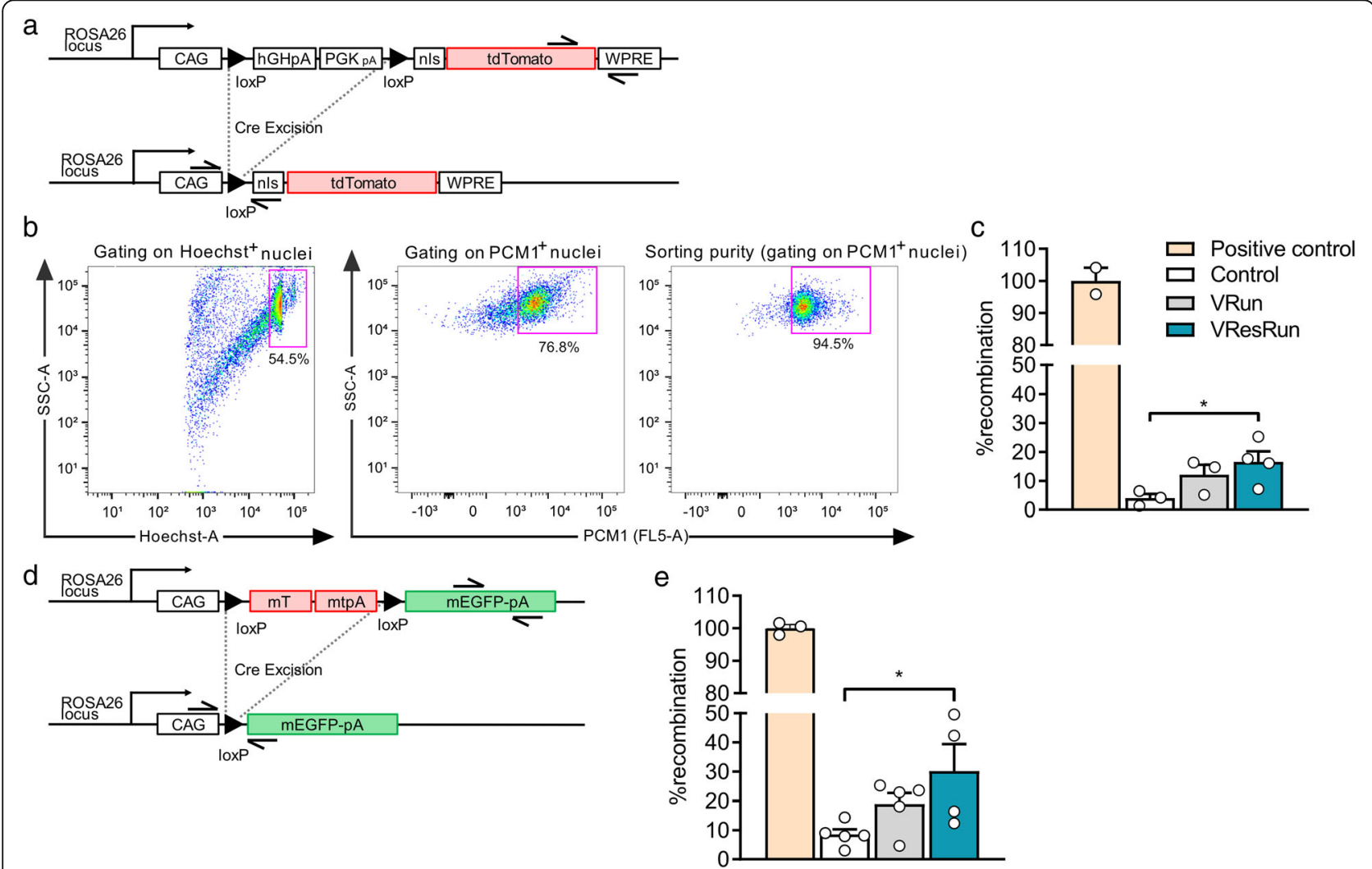

Fig. 5 Myonuclear-specific Cre-mediated recombination. a Schematic diagram of the Rosa ${ }^{\text {CAG-ls-ntdTomato }}$ construct before and after Cre-mediated recombination. Representation of primers used for quantitative RT-PCR analysis showing amplicon of recombinant DNA and amplicon of internal control for normalization. $\mathbf{b}$ Representative flow cytometry plots depicting the gating strategy for sorting of myonuclei. Isolated nuclei were analyzed by side scatter (SSC) and Hoechst. Hoechst ${ }^{+} \mathrm{PCM}^{+}$single nuclei were sorted for further analysis. Purity of sorted myonuclei is shown in

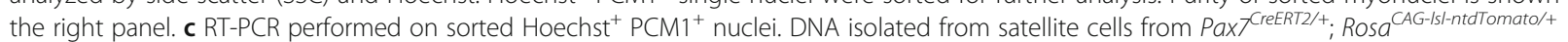
mice with the presence of one recombined allele in each satellite cell served as a 100\% reference (positive control). $\mathbf{d}$ Schematic diagram of the Rosa $^{\text {mTmG }}$ construct before and after Cre-mediated recombination. Representation of primers used for quantitative RT-PCR analysis showing amplicon of recombinant DNA and amplicon of internal control for normalization. e RT-PCR performed on genomic DNA isolated from bulk muscle. DNA isolated from tamoxifen injected $\mathrm{HSA}^{\mathrm{icre} /+}$; Rosa ${ }^{\mathrm{mTmG} /+}$ mice with the presence of one recombined allele in each myonucleus, served as a 100\% reference (positive control). Recombination rates were calculated from the relative expression of recombined levels normalized for internal control. Statistics, one-way ANOVA test with Tukey correction for multiple comparisons $\left({ }^{*} p<0.05 ;{ }^{* *} p<0.01\right.$; $\left.{ }^{* *} p<0.001\right)$. Each dot represents a single mouse. Bar graphs represent mean \pm SEM (error bars) 
studies have reported hypertrophy during short term (48 weeks) voluntary free wheel running $[17,23]$ while others failed to do so [34]. Likely, the effects of shortterm voluntary free wheel running are minor and potentially only reach significance when corrected for body weight [23]. Against this background, we found significant SC contribution to muscle where we did not observe hypertrophy. More specifically, we report SC contribution (in both MHCI as well as MHCIIa fibers) of SOL upon VRun. We also show SC contribution to MHCI fibers in SOL upon VResRun, which did not exhibit enhanced fiber cross sectional area. Finally, we also found increased myonuclear density in GAS, despite lack of increased muscle weight. Thus, our data shows that SC fusion can be uncoupled of muscle hypertrophy under specific conditions.

The potential signals promoting exercise-induced SCto-myonuclear contribution remain elusive and have been hypothesized to be both local and systemic. When rodents walk or run, most of the work is performed by the plantar flexors. The dorsi flexors undergo much less mechanical load since they only keep the foot up in the swing phase [45]. In this respect, recent work from our group has shown that acute VResRun increases mTORC1 signaling exclusively in SOL, PLT, and the oxidative part of the GAS but not in TA [42]. Moreover, muscle hypertrophy is predominantly observed in plantar flexors upon resistance running, as opposed to dorsi flexors $[24,34,46]$. Using Pax $7^{\operatorname{CreERT2/+}} ; \operatorname{Ros}^{m T m G /+}$ mice, we show that voluntary running strongly increases SC fusion in the plantar flexors SOL and PLT, partially in the GAS, and not in EDL or TA dorsiflexors. Furthermore, adding resistance to the wheel further increased $\mathrm{SC}$ fusion, indicating that the extra muscular work independently promotes SC fusion. Detailed analyses of myonuclear accretion via immunostainings of PCM1 and nuclei count on single fibers when compared to satellite cell tracing at the DNA level confirm that loaddependent augmentation of SC fusion corroborates very well with increases in myonuclear number. Thus, our data suggests that local rather than systemic signals regulate exercise-induced $\mathrm{SC}$ fusion and subsequent myonuclear accretion.

Our study did not focus on elucidating whether or not satellite cell contribution to myonuclei is driven by muscle damage or a consequence of exercise-dependent signals. We could not detect $\mathrm{eMHC}^{+}$fibers in VRun nor VResRun. This shows that at the time of muscle sampling (8 weeks of running), no active regeneration was ongoing. Studies have shown that high intensity exercise (predominantly eccentric exercise) leads to muscle damage which is associated with satellite cell activation [4749]. However, recent work has also shown that local injury occurs in exercising muscle but that this might not be responsible for widespread SC activation upon resistance type exercise [50]. Thus, the mechanisms that promote SC activation, proliferation, and fusion upon exercise/load are likely to be different when compared to injury-induced regeneration. Potentially, even temporal differences between different stimuli exist [8]. Since myonuclear accumulation occurs gradually during training [8], it is unlikely that it is exclusively driven by damage. Future studies will need to reveal the exact contribution of both mechanisms to exercise-induced myonuclear accumulation.

Whether SCs are required for muscle hypertrophy is a heavily debated topic [51] and likely depends on age, genetic mutation, models used to induce hypertrophy, and time of sampling after the applied stimulus $[6,8$, 19-21, 25, 52, 53]. Moreover, impairing SC contribution by the frequently used $\operatorname{Pax} 7^{\text {CreER-DTA }}$ model might evoke undesirable adaptations such as impairments of proprioception and reduced voluntary wheel running, which do not reflect physiological circumstances [16]. Although we could not causally link SC fusion with hypertrophy in this study since we used reporter models to trace SC contributions under physiological circumstances, our tracing approach allows us to evaluate whether SC fusion occurs upon exercise and whether concomitant myonuclear accretion occurs in the absence or presence of hypertrophy. VResRun induced a $23 \%$ increase in SOL wet weight, which was exclusively caused by the increase in CSA of MyHCIIa fibers, while no hypertrophy was observed in VRun in any fiber type. This is remarkable given that even though SC fusion was higher in VResRun, we observed similar numbers of GFP positive MyHCI versus MyHCIIa fibers in both VRun and VResrun. Thus, the lack of hypertrophy in the heavily SC fused MyHCI fibers promotes the hypothesis that myonuclear accretion might also play a role in endurance adaptations to interval training $[11,54]$ and that myonuclear accretion is not merely a way to withstand to expansion of the myonuclear domain [55].

The $P a x 7^{m T m G /+}$ mice only provide a rough estimation of SC contribution to myonuclei under exercise conditions since the mGFP diffuses throughout the sarcolemma. Therefore, to get a quantitative insight into the extent of SC contribution to myonuclei, we used a nuclear reporter mouse in which the fluorescent reporter (nTom) is retained exclusively within the Pax $7^{+}$cells and all SC-derived myonuclei. Strikingly, we found that nearly all myonuclei became $\mathrm{nTom}^{+}$after 8 weeks of VRun and VResRun, despite only a modest $14 \%$ and $16 \%$ increase in myonuclear number by VRun and VResRun respectively. During the preparation of this manuscript, an extensive report provided direct evidence of fluorescent protein traveling between nuclei of primary differentiated myotubes, a phenomenon termed nuclear 
propagation [44]. In concordance, spatial distribution of specific transcription factors, which may exit the myonucleus and activate receptors in other regions of the myofiber has been reported [56], suggesting nuclear transport of various proteins between nuclei in myofibers. We confirmed propagation in our model by a series of co-culturing experiments using H2B-nGFP and nTom expressing myoblasts. After 6 days of differentiation, when myotubes reached full differentiation, nearly $60 \%$ of all nuclei became nTom ${ }^{+}$, while WT and nTom were initially seeded at a 1 to 4 ratio. Similar results were obtained when $\mathrm{nTom}^{+}$, and $\mathrm{H} 2 \mathrm{~B}-\mathrm{nGFP}^{+}$myoblasts were differentiated in the same culture. Thus, the high number of $\mathrm{nTom}^{+}$myonuclei, which we observed after voluntary running, is a vast overestimation of SC fusion. Importantly, these data warrant against the use of nuclear reporter mice in multinucleated cells such as myofibers and suggest a careful re-interpretation of previous data published with $\operatorname{Pax} 7$ nuclear reporter mice [57-59].

To circumvent nuclear propagation artifacts in our $\operatorname{Pax} 7^{n T o m /+}$ mice, we assessed recombination at the DNA level from both sorted myonuclei as well as bulk muscle derived from two Pax7 reporter models. Intriguingly, the increase in the fraction of recombined myonuclei from sedentary control to VRun $(+8 \%)$ and (VResRun) (+12\%) was almost identical to the increases in myonuclear accretion measured on single fiber $\left(\right.$ Hoechst $\left.^{+}\right)$and on cryosections $\left(\mathrm{PCM}^{+}\right)$. Myonuclei have a half-life of at least 15 years [60] and are remarkably resistant to apoptosis, even when the myofiber is challenged by unloading or atrophy [61]. This suggests that myonuclear turnover during exercise training is low and that the $\sim 16 \%$ increase in myonuclei upon exercise as observed in this study is the direct result of SC fusion to myofibers, without active nuclear apoptosis. Thus, based on our data, a major question that arises is whether these new myonuclei are different in terms of transcriptional or epigenetic signature from the old residing ones. In addition, whether they contribute to training adaptations and whether there is a difference between endurance and resistance-based training is yet to be explored. Future research using single nuclei transcriptomics may elucidate potential reprogramming of newly derived myonuclei during exercise.

\section{Conclusions}

In summary, this study is the first to assess SC fusion and concomitant myonuclear accretion in a physiological setting of increased mechanical load. Using a $\operatorname{Pax} 7$ membrane-marker reporter, we show increased loaddependent SC fusion in the plantar flexors of the mouse hind limb after 8 weeks of voluntary running. Predominantly, the glycolytic type MyHCIIa fibers in SOL underwent hypertrophy, but SC contribution occurred to the same extent in both in MyHCI and MyHCIIa fibers. Thus, the lack of hypertrophy in the heavily SC fused $\mathrm{MyHCI}$ fibers strongly suggests that myonuclear accretion might also play a role in endurance adaptations to interval training. Furthermore, in an attempt to objectively quantify SC-derived myonuclear accretion after voluntary running, we used a $\operatorname{Pax} 7$ nuclear reporter mouse and unexpectedly observed massive increase in nTom positive nuclei. Further in vitro co-culture experiments showed that this was due to propagation of nTom between nuclei sharing the same cytoplasm. Hence, future investigations should warrant caution in using nuclear reporter constructs in multinucleated cells. Finally, assessment of Cre-mediated recombination in Pax 7 CreERT2 reporter models indicated that SC contribution to myofibers mirrors myonuclear accretion during exercise.

\section{Supplementary information}

Supplementary information accompanies this paper at https://doi.org/10. 1186/s13395-020-00237-2.

\begin{abstract}
Additional file 1: Figure S1. Running pattern. (A) Average running speed, (B) running time and (C) number of bouts per night throughout the exercise protocol ( $n=16$ mice per group). Statistics: two-way ANOVA test with a Bonferroni post hoc test. Group $x$ time interaction is indicated in the figure. $\left({ }^{*} p<0.05 ;{ }^{* *} p<0.01 ;{ }^{* * *} p<0.001\right)$. Line graphs represent mean \pm SEM (error bars)
\end{abstract}

Additional file 2: Figure S2. Muscle hypertrophy is muscle dependent, fiber type dependent and load-dependent. (A) Representative crosssections for $\mathrm{m}$. soleus (SOL) stained for $\mathrm{MyHCl}$ (green), MyHClla (blue) and Laminin (red). (B,C) Quantification of fiber cross-sectional area distribution and $(\mathrm{D}, \mathrm{E})$ average fiber cross-sectional area. (F) Representative cross-sections for plantaris (PLT) stained for MyHClla (blue), MyHCllb (yellow) and laminin. $(\mathrm{G}, \mathrm{H})$ quantification of fiber cross-sectional area distribution and $(\mathrm{I}, \mathrm{J})$ average fiber cross-sectional area. (K) Fiber cross-sectional area distribution for gastrocnemius (GAS), (L) tibialis anterior (TA) and (M) extensor digitorum longus (EDL). Statistics: one-way ANOVA test with Tukey correction for multiple comparisons $\left({ }^{*} p<0.05 ;{ }^{* *} p<0.01 ;{ }^{* *} p<\right.$ 0.001) (a, $p<0.05$ VResRun compared to Control; $b, p<0.05$ VResRun compared to VRun; c, $p<0.05$ VRun compared to Control). Bar graphs and line graphs represent mean \pm SEM (error bars). Scale bar, $100 \mu \mathrm{m}$.

Additional file 3: Figure S3. Fiber remodeling and central nuclei. (A) Myofibers stained for embryonic myosin heavy chain (eMHC), laminin and hoechst. No eMHC ${ }^{+}$fibers were detected in Control, VRun, VResRun. Glycerol injected muscle was used as a positive control. (B) Quantification of fibers containing one or more centrally located nucleus. Arrows indicate central nuclei. Bar graph represents mean \pm SEM (error bars). Statistics: one-way ANOVA test with Tukey correction for multiple comparisons $\left({ }^{*} p<0.05\right)$. Each dot represents a single mouse. Scale bar, 50 $\mu \mathrm{m}$.

Additional file 4: Figure S4. SC fusion is not fiber type dependent. (A) Representative sequential cross-sections for soleus for mGFP and mTomato (left panel) and stained for $\mathrm{MyHCl}$ (yellow) and MyHClla (blue) (right panel). (B) Quantification of $\mathrm{GFP}^{+}$fibers for $\mathrm{MyHCl}$ and (C) MyHClla. (D) Fiber type distribution and (E) fiber type distribution of $\mathrm{GFP}^{+}$fibers. Statistics: one-way ANOVA test with Tukey correction for multiple comparisons $\left({ }^{*} p<0.05 ;{ }^{* *} p<0.01 ;{ }^{* * *} p<0.001\right)$. Each dot represents a single mouse. Bar graphs and line graphs represent mean \pm SEM (error bars). White arrows indicate $\mathrm{GFP}^{+} \mathrm{MyHCl}^{+}$fibers, purple arrows indicate $\mathrm{GFP}^{+} \mathrm{MyHClla}^{+}$ fibers. Scale bar, $100 \mu \mathrm{m}$.

Additional file 5: Figure S5. Myonuclear accretion is load-dependent (A) Representative cross-sections of soleus, plantaris and gastrocnemius stained for PCM1 (yellow) and Hoechst (blue). (B) Quantification of 
$\mathrm{PCM}^{+} / \mathrm{Hoechst}^{+}$nuclei per fiber. Statistics: one-way ANOVA test with Tukey correction for multiple comparisons $\left({ }^{*} p<0.05 ;{ }^{* *} p<0.01 ;{ }^{* * *} p<\right.$ $0.001)$. Bar graphs and line graphs represent mean \pm SEM (error bars). White arrows indicate $\mathrm{PCM}^{+}$nuclei. Scale bar, $50 \mu \mathrm{m}$.

Additional file 6: Video S1. In vitro nuclear propagation. Time-lapse epifluorescence microscopy of a fusing $\mathrm{nTom}^{+}$myoblast with WT myoblasts (nTom). White arrow shows propagation of nTom. Scale bar, $50 \mu \mathrm{m}$.

Additional file 7: Table S1. Phenotypic characterization and muscle weights normalized to tibia length. Statistics: one-way ANOVA test with Tukey correction for multiple comparisons $(* p<0.05$ VResRun vs. Control). Values represent mean \pm SEM. $n=9-12$ mice per group.

\section{Abbreviations}

SC: Satellite cell; TA: Tibialis anterior; EDL: Extensor digitorum longus; SOL: Soleus; PLT: Plantaris; GAS: Gastrocnemius; PAX7: Paired Box Protein 7; mTomato: Membrane-bound Tomato; ntdTom: Nuclear tdTomato; mGFP: Membrane-bound Green Fluorescent Protein; PCM1: Pericentriolar material 1; MyHC: Myosin heavy chain; mTORC1: Mammalian target of rapamycin; CSA: Cross-sectional area

\section{Acknowledgements}

We gratefully acknowledge Nicola Bundschuh and Paola Gilardoni for their skilled technical assistance and Andrew Palmer for his thoughtful discussions about the experiments.

\section{Authors' contributions}

Evi Masschelein, conceptualization, data curation, formal analysis, investigation, methodology, writing original draft, and review and editing; Gommaar D'Hulst, conceptualization, data curation, formal analysis, investigation, methodology, writing original draft, and review and editing; Laura Hinte, formal analysis, methodology, and manuscript editing; Joel Zvick, formal analysis, methodology, and manuscript editing; Inés SoroArnaiz, formal analysis, methodology, and manuscript editing; Tatiane Gorski, formal analysis, methodology, and manuscript editing; Ferdinand von Meyenn, conceptualization, investigation, and manuscript editing; Ori BarNur, conceptualization, investigation, and manuscript editing; and Katrien De Bock, conceptualization, formal analysis, funding acquisition, investigation, methodology, writing original draft, project administration, and editing. The author(s) read and approved the final manuscript.

\section{Funding}

ETH Zurich internal funding

\section{Availability of data and materials}

The datasets used and/or analyzed during the current study are available from the corresponding author on reasonable request.

\section{Ethics approval}

All animal procedures were approved by the Veterinary office of the Canton of Zürich (license nr. ZH254-16).

\section{Consent for publication}

Not applicable

\section{Competing interests}

The authors declare that they have no competing interests.

\section{Author details}

'Department Health Sciences and Technology, Laboratory of Exercise and Health, Swiss Federal Institute of Technology (ETH) Zurich, Zurich, Switzerland. ${ }^{2}$ Department Health Sciences and Technology, Laboratory of Regenerative and Movement Biology, Swiss Federal Institute of Technology (ETH) Zurich, Zurich, Switzerland. ${ }^{3}$ Department Health Sciences and Technology, Laboratory of Nutrition and Metabolic Epigenetics, Swiss Federal Institute of Technology (ETH) Zurich, Zurich, Switzerland.
Received: 27 March 2020 Accepted: 15 June 2020

Published online: 09 July 2020

\section{References}

1. Caiozzo VJ. Plasticity of skeletal muscle phenotype: mechanical consequences. Muscle Nerve. 2002;26:740-68.

2. Morton RW, Murphy KT, McKellar SR, Schoenfeld BJ, Henselmans M, Helms

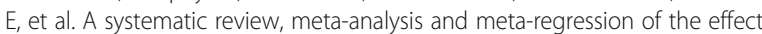
of protein supplementation on resistance training-induced gains in muscle mass and strength in healthy adults. Br J Sports Med. 2017:bjsports-2017097608 Available from: http://bjsm.bmj.com/lookup/doi/10.1136/bjsports-2 017-097608

3. Chargé SBP, Rudnicki MA. Cellular and molecular regulation of muscle regeneration. Physiol Rev. 2004;84:209-38.

4. Tierney MT, Sacco A. Satellite cell heterogeneity in skeletal muscle homeostasis. Trends Cell Biol [Internet]. Elsevier Ltd. 2016;26:434-44 Available from: https://doi.org/10.1016/j.tcb.2016.02.004.

5. Dungan CM, Murach KA, Frick KK, Jones SR, Crow SE, Englund DA, et al. Elevated myonuclear density during skeletal muscle hypertrophy in response to training is reversed during detraining. Am J Physiol Physiol. 2019;316:C649-54

6. Goh Q, Millay DP. Requirement of myomaker-mediated stem cell fusion for skeletal muscle hypertrophy. Elife. 2017;6:1-19.

7. Fry CS, Lee JD, Jackson JR, Kirby TJ, Stasko SA, Liu H, et al. Regulation of the muscle fiber microenvironment by activated satellite cells during hypertrophy. FASEB J. 2014:28:1654-65.

8. Goh Q, Song T, Petrany MJ, Cramer AA, Sun C, Sadayappan S, et al. Myonuclear accretion is a determinant of exercise-induced remodeling in skeletal muscle. Elife. 2019;8:1-19.

9. Keefe AC, Lawson JA, Flygare SD, Fox ZD, Colasanto MP, Mathew SJ, et al. Muscle stem cells contribute to myofibres in sedentary adult mice. Nat Commun Nature Publishing Group. 2015;6:1-11.

10. Pawlikowski B, Pulliam C, Betta ND, Kardon G, Olwin BB. Pervasive satellite cell contribution to uninjured adult muscle fibers. Skelet Muscle. 2015;5:113 Available from: https://doi.org/10.1186/s13395-015-0067-1.

11. Abreu P, Mendes SVD, Ceccatto VM, Hirabara SM. Satellite cell activation induced by aerobic muscle adaptation in response to endurance exercise in humans and rodents. Life Sci. 2017;170:33-40 Available from: https://doi. org/10.1016/j.lfs.2016.11.016.

12. Cisterna B, Giagnacovo M, Costanzo M, Fattoretti P, Zancanaro C, Pellicciari $C$, et al. Adapted physical exercise enhances activation and differentiation potential of satellite cells in the skeletal muscle of old mice. J Anat. 2016; 228:771-83.

13. Shefer G, Rauner G, Yablonka-Reuveni Z, Benayahu D. Reduced satellite cell numbers and myogenic capacity in aging can be alleviated by endurance exercise. PLoS One. 2010;5.

14. Kurosaka M, Naito H, Ogura Y, Kojima A, Goto K, Katamoto S. Effects of voluntary wheel running on satellite cells in the rat plantaris muscle. Sports Sci Med. 2009;8:51-7.

15. Smith HK, Merry TL. Voluntary resistance wheel exercise during post-natal growth in rats enhances skeletal muscle satellite cell and myonuclear content at adulthood. Acta Physiol. 2012;204:393-402.

16. Jackson JR, Kirby TJ, Fry CS, Cooper RL, Mccarthy JJ, Peterson CA, et al. Reduced voluntary running performance is associated with impaired coordination as a result of muscle satellite cell depletion in adult mice. Skelet Muscle [Internet]. Skelet Muscle; 2015;1-17. Available from: https:// doi.org/10.1186/s13395-015-0065-3.

17. Li P, Akimoto T, Zhang M, Williams RS, Yan Z. Resident stem cells are not required for exercise-induced fiber-type switching and angiogenesis but are necessary for activity-dependent muscle growth. Am J Phys Cell Phys. 2006; 290:1461-8.

18. De Bono JP, Adlam D, Paterson DJ, Channon KM. Novel quantitative phenotypes of exercise training in mouse models. Am J Physiol Integr Comp Physiol. 2005;290:R926-34.

19. O'Connor RS, Pavlath GK, McCarthy JJ, Esser KA. Last word on point: counterpoint: satellite cell addition is/is not obligatory for skeletal muscle hypertrophy. J Appl Physiol. 2007;103:1107.

20. Murach KA, Fry CS, Kirby TJ, Jackson JR, Lee JD, White SH, et al. Starring or supporting role? Satellite cells and skeletal muscle fiber size regulation. Physiology (Bethesda). 2018;33:26-38 Available from: http://ovidsp.ovid. com/ovidweb.cgi?T=JS\&PAGE=reference\&D=prem\&NEWS=N\&AN=29212890 
21. Cornelison DDW. "Known Unknowns": current questions in muscle satellite cell biology. 1st Curr. Top. Dev. Biol. Elsevier Inc.; 2018. Available from: https://doi.org/10.1016/bs.ctdb.2017.08.006.

22. Soffe Z, Radley-Crabb HG, McMahon C, Grounds MD, Shavlakadze T. Effects of loaded voluntary wheel exercise on performance and muscle hypertrophy in young and old male C57BI/6J mice. Scand J Med Sci Sports. 2016;26:172-88

23. Legerlotz K, Elliott B, Guillemin B, Smith HK. Voluntary resistance running wheel activity pattern and skeletal muscle growth in rats. Exp Physiol. 2008; 93:754-62.

24. White Z, Terrill J, White RB, McMahon C, Sheard P, Grounds MD, et al. Voluntary resistance wheel exercise from mid-life prevents sarcopenia and increases markers of mitochondrial function and autophagy in muscles of old male and female C57BL/6J mice. Skelet Muscle. 2016;6:1-21 Available from: https://doi.org/10.1186/s13395-016-0117-3.

25. Mccarthy JJ, Dupont-versteegden EE, Fry CS, Murach KA, Peterson CA. Methodological issues limit interpretation of negative effects of satellite cell depletion on adult muscle hypertrophy. Development. 2017;144:1363-7.

26. Manzanares G, Brito-Da-Silva G, Gandra PG. Voluntary wheel running: patterns and physiological effects in mice. Braz J Med Biol Res. 2019;52:1-9.

27. Bergmeister KD, Gröger M, Aman M, Willensdorfer A, Manzano-Szalai K, Salminger $\mathrm{S}$, et al. Automated muscle fiber type population analysis with Image of whole rat muscles using rapid myosin heavy chain immunohistochemistry. Muscle Nerve. 2016;54:292-9.

28. Winje IM, Bengtsen M, Eftestø| E, Juvkam I, Bruusgaard JC, Gundersen K. Specific labelling of myonuclei by an antibody against pericentriolar material 1 (PCM1) on skeletal muscle tissue sections. Acta Physiol. 2018;12:e13034.

29. Tierney MT, Stec MJ, Sacco A. Assessing muscle stem cell clonal complexity during aging. In: Turksen K, editor. Methods Mol Biol vol 2045. New York: Humana; 2018.

30. Noirez P, Torres S, Cebrian J, Agbulut O, Peltzer J, Butler-Browne G, et al. TGF- $\beta 1$ favors the development of fast type identity during soleus muscle regeneration. J Muscle Res Cell Motil. 2006:1-8.

31. D'Hulst G, Soro-Arnaiz I, Masschelein E, Veys K, Fitzgerald G, Smeuninx B, et al. PHD1 controls muscle mTORC1 in a hydroxylation-independent manner by stabilizing leucyl tRNA synthetase. Nat Commun Springer US. 2020;11:1-15.

32. Habib N, Avraham-Davidi I, Basu A, Burks T, Shekhar K, Hofree M, et al. Massively parallel single-nucleus RNA-seq with DroNc-seq. Nat Methods. 2017;14:955-8

33. McCarthy JJ, Srikuea R, Kirby TJ, Peterson CA, Esser KA. Inducible Cre transgenic mouse strain for skeletal muscle-specific gene targeting. Skelet Muscle. 2012:1-7.

34. Konhilas JP, Widegren U, Allen DL, Paul AC, Cleary A, Leinwand LA. Loaded wheel running and muscle adaptation in the mouse. Am J Physiol Circ Physiol. 2005;289:H455-65.

35. Egner IM, Bruusgaard JC. Gundersen K. Development: Satellite cell depletion prevents fiber hypertrophy in skeletal muscle; 2016.

36. Murach KA, White SH, Wen Y, Ho A, Dupont-Versteegden EE, McCarthy JJ, et al. Differential requirement for satellite cells during overload-induced muscle hypertrophy in growing versus mature mice. Skelet Muscle. 2017;7:1-13.

37. Murphy MM, Keefe AC, Lawson JA, Flygare SD, Yandell M, Kardon G. Transiently active wnt/B-catenin signaling is not required but must be silenced for stem cell function during muscle regeneration. Stem Cell Reports. 2014;3: 475-88 Available from: https://doi.org/10.1016/j.stemcr.2014.06.019.

38. Muzumdar MD, Tasic B, Miyamichi K, Li L, Luo L. A global doublefluorescent Cre reporter mouse. Genesis. 2007:45:593-605.

39. Pallafacchina $G$, Blaauw B, Schiaffino S. Role of satellite cells in muscle growth and maintenance of muscle mass. Nutr Metab Cardiovasc Dis. 2013; 23:12-8 Available from: https://doi.org/10.1016/j.numecd.2012.02.002.

40. White RB, Biérinx A, Gnocchi VF, Zammit PS. Dynamics of muscle fibre growth during postnatal mouse development. BMC Dev Biol. 2010;10:1-11.

41. Bruusgaard JC, Liestø K, Gundersen K. Distribution of myonuclei and microtubules in live muscle fibers of young, middle-aged, and old mice. J Appl Physiol. 2006;100:2024-30.

42. D'Hulst G, Palmer SP, Masschelein E, Bar-Nur O, De Bock K. Voluntary resistance running as a model to induce $\mathrm{mTOR}$ activation in mouse skeletal muscle. Front Physiol. 2019;10:1-9.

43. Yan Z, Okutsu M, Akhtar YN, Lira VA. Regulation of exercise-induced fiber type transformation, mitochondrial biogenesis, and angiogenesis in skeletal muscle. J Appl Physiol. 2011;110:264-74.
44. Taylor-weiner H, Grigsby CL, Ferreira DMS, Dias JM, Stevens MM. Modeling the transport of nuclear proteins along single skeletal muscle cells. Proc Nat Acad Sci. 2020:1-9.

45. Carlson-Kuhta P, Trank TV, Smith JL. Forms of forward quadrupedal locomotion. III. A comparison of posture, hindlimb kinematics, and motor patterns for downslope and level walking. J Neurophysiol. 1998;79:1702-16.

46. Call JA, Mckeehen JN, Novotny SA, Lowe DA. Progressive resistance voluntary wheel running in the mdx mouse. Muscle Nerve. 2010;42:871-80.

47. Dreyer HC, Blanco CE, Sattler FR, Schroeder ET, Wiswell RA. Satellite cell numbers in young and older men 24 hours after eccentric exercise. Muscle Nerve. 2006;33:242-53.

48. Crameri RM, Langberg $\mathrm{H}$, Magnusson $\mathrm{P}$, Jensen $\mathrm{CH}$, Schrøoder HD, Olesen $J$, et al. Changes in satellite cells in human skeletal muscle after a single bout of high intensity exercise. J Physiol. 2004;558:333-40.

49. Parise G, McKinnell IW, Rudnicki MA. Muscle satellite cell and atypical myogenic progenitor response following exercise. Muscle Nerve. 2008;37: 611-9.

50. Fukuda S, Kaneshige A, Kaji T, Noguchi YT, Takemoto Y, Zhang L, et al. Sustained expression of HeyL is critical for the proliferation of muscle stem cells in overloaded muscle. Elife. 2019;8:1-21.

51. Egner IM, Bruusgaard JC, Gundersen K. An apparent lack of effect of satellite cell depletion on hypertrophy could be due to methodological limitations. Response to 'Methodological issues limit interpretation of negative effects of satellite cell depletion on adult muscle hypertrophy.'. Development. 2017; 144:1365-7

52. Blaauw B, Canato M, Agatea L, Toniolo L, Mammucari C, Masiero E, et al. Inducible activation of Akt increases skeletal muscle mass and force without satellite cell activation. FASEB J. 2009;23:3896-905.

53. Raffaello A, Milan G, Masiero E, Carnio S, Lee D, Lanfranchi G, et al. JunB transcription factor maintains skeletal muscle mass and promotes hypertrophy. J Cell Biol. 2010;191:101-13.

54. Hawley JA, Hargreaves M, Joyner MJ, Zierath JR. Integrative biology of exercise. Cell. 2014;159:738-49 Available from: https://doi.org/10.1016/j.cell. 2014.10.029

55. Conceiçao M, Vechin FC, Lixandrão ME, Damas F, Libardi CA, Tricoli V, et al. Muscle fiber hypertrophy and myonuclei addition. Med Sci Sports Exerc. 2018:50:1385-93 Available from: http://insights.ovid.com/crossref?an=00005 768-201807000-00006

56. Fontaine B, Sassoon D, Buckingham M, Changeux JP. Detection of the nicotinic acetylcholine receptor alpha-subunit mRNA by in situ hybridization at neuromuscular junctions of 15-day-old chick striated muscles. EMBO J. 1988:7:603-9.

57. Bachman JF, Klose A, Liu W, Paris ND, Blanc RS, Schmalz M, et al. Prepubertal skeletal muscle growth requires Pax7-expressing satellite cellderived myonuclear contribution. Development. 2018;145:dev167197.

58. Tierney MT, Stec MJ, Rulands S, Simons BD, Sacco A. Muscle stem cells exhibit distinct clonal dynamics in response to tissue repair and homeostatic aging. Cell Stem Cell. 2017;22:119-27 Available from: http:// linkinghub.elsevier.com/retrieve/pii/S1934590917304617.

59. Liu W, Klose A, Forman S, Paris ND, Wei-LaPierre L, Cortés-Lopéz M, et al. Loss of adult skeletal muscle stem cells drives age-related neuromuscular junction degeneration. Elife. 2017;6:1-15.

60. Spalding KL, Bhardwaj RD, Buchholz BA, Druid H, Frisén J. Retrospective birth dating of cells in humans. Cell. 2005;122:133-43.

61. Bruusgaard JC, Gundersen K. In vivo time-lapse microscopy reveals no loss of murine myonuclei during weeks of muscle atrophy. J Clin Invest. 2008; 118:1450-7.

\section{Publisher's Note}

Springer Nature remains neutral with regard to jurisdictional claims in published maps and institutional affiliations. 